\title{
SIZE CONSTANGY BY THE METHOD OF SINGLE STIMULI A METHODOLOGICAL STUDY ${ }^{1}$
}

\author{
TAKEHIRO UENO
}

\author{
Osaka City University
}

\begin{abstract}
From the point of view of measurement models, size constancy of a single object was investigated by using three-dimensional familiar and unfamiliar objects. Two measurement models were applied to a stimulus series. One measurement model referred to perceived size and another assumed size. Presentation distance of the stimuli ranged from $1 \mathrm{~m}$ to $5 \mathrm{~m}$ apart from the $O$. The results are: (a) Constancy of assumed size was higher than that of perceived size. (b) Both assumed size and perceived size showed slightly a tendency to increase with increasing distance. The concept of size was discussed with the two measurement models.
\end{abstract}

Since Martius (1889), a great deal of experimentation has been done with respect to size constancy. However, most investigations are concerned with size constancy in two stimuli comparison situation, in which the observer is required to make comparative judgments between the standard and comparison stimuli presented at different distances.

From a methodological point of view, a clear distinction must be made between size constancy in two stimuli comparison situation and size constancy in single stimuli situation (Makino \& Ueno, 1963).

Size estimation of a single object can be made by so-called absolute or single stimuli judgments. Some demonstrational works exist, which are closely relevant to this type of size constancy (e.g., Ittelson, 1951a; Makino, 1954; Brunswik, 1956; Bolles \& Bailey, 1956; Mckennell, 1960; Over, 1963; Makino \& Ueno, 1963).

In the present investigation, an attempt was made to examine size constancy by the method of single stimuli within a framework of measurement theory, which had been developed by Coombs (1952, 1953, 1960).

\section{Two Measurement Models}

From the point of view of measurement models, data contain information as to either order relation or proximity relation
(Coombs, 1960). In general, order relation is obtainable by judging a stimulus with respect to its relative position among other stimuli. We shall designate this type of measurement as Measurement Model I.

Data of proximity relation, on the other hand, can be obtained by judging a stimulus against some absolute standard or personal reference point. We shall designate this kind of measurement as Measurement Model II².

\section{EXPERIMENT I}

The principal purpose of the present experiment consisted in collecting data as to size constancy of a single object in terms of Measurement Models I and II. Threedimensional familiar object was used as stimulus-object.

Observers. Six undergraduate students, majored in psychology at Osaka City University, served as $O$ s. All had normal vision or were corrected normal. Three of them participated

1 The present writer wishes to express his deep gratitude to Assistant Professors T. Makino and M. Ikuzawa for their valuable advices and critical readings of the manuscript.

${ }^{2}$ Order relation and proximity relation correspond respectively to "Task B" and "Task A" in early formulations of a theory of data (Coombs, 1952, $1953)$. 
TABLE 1

Frequencies with which each stimulus was assigned to "middle" category at each distance

\begin{tabular}{|c|c|c|c|c|c|c|}
\hline \multirow{2}{*}{$\begin{array}{l}\text { Physical } \\
\text { distance }\end{array}$} & \multicolumn{5}{|c|}{ Stimulus } & \multirow{2}{*}{$\begin{array}{l}\text { Perceived } \\
\text { size }\end{array}$} \\
\hline & $6.5 \mathrm{~cm}$ & 7.1 & 7.8 & 8.6 & 9.6 & \\
\hline $1 \mathrm{~m}$ & 3 & 21 & 37 & 17 & 4 & $7.80 \mathrm{~cm}$ \\
\hline 2 & 1 & 32 & 43 & 21 & & 7.71 \\
\hline 3 & & 22 & 37 & 27 & 2 & 7.89 \\
\hline 4 & 2 & 19 & 31 & 29 & 3 & 7.92 \\
\hline 5 & 5 & 19 & 34 & 31 & 4 & 7.90 \\
\hline
\end{tabular}

TABLE 2

Frequencies with which each stimulus was assigned to "same" category at each distance

\begin{tabular}{|c|c|c|c|c|c|c|}
\hline \multirow{2}{*}{$\begin{array}{l}\text { Physical } \\
\text { distance }\end{array}$} & \multicolumn{5}{|c|}{ Stimulus } & \multirow{2}{*}{$\underset{\text { size }}{\text { Assumed }}$} \\
\hline & $5.9 \mathrm{~cm}$ & 6.5 & 7.1 & 7.8 & 8.6 & \\
\hline $1 \mathrm{~m}$ & 3 & 19 & 20 & 15 & & $7.00 \mathrm{~cm}$ \\
\hline 2 & 1 & 14 & 32 & 23 & 1 & 7.19 \\
\hline 3 & & 10 & 28 & 27 & 7 & 7.40 \\
\hline 4 & 5 & 14 & 31 & 26 & 3 & 7.18 \\
\hline 5 & & 3 & 33 & 34 & 2 & 7.44 \\
\hline
\end{tabular}

in Measurement Model I first and II second; the other three in the reverse order.

Stimuli and stimulus arrangements. A cigarettepackage "Peace" was selected as a sample of three-dimensional familiar object. The normal size of the package is $7.1 \mathrm{~cm}$ in height, $4.3 \mathrm{~cm}$ in width and $1.7 \mathrm{~cm}$ in depth, and its color is dark blue. Each member of the cigarettepackage stimuli was made photographically from a negative. The stimulus series consisted of 11 cigarette-packages : $4.4,4.9,5.3,5.9,6.5$, $7.1,7.8,8.6,9.5,10.4$ and $11.4 \mathrm{~cm}$ in height. Needless to say, width and depth of these stimuli were proportional to their height. This series is geometric and its ratio is approximately 1.10. Notice that the middle of the series was equal to the normal-size package.

Presentation distances of the stimuli were 1 , 2, 3, 4 and $5 \mathrm{~m}$ apart from $O$. The stimuli were attached, one at a time, to a vertically standing black pole at each distance, and were fixed at $O$ 's eye-level, $125 \mathrm{~cm}$ in height.

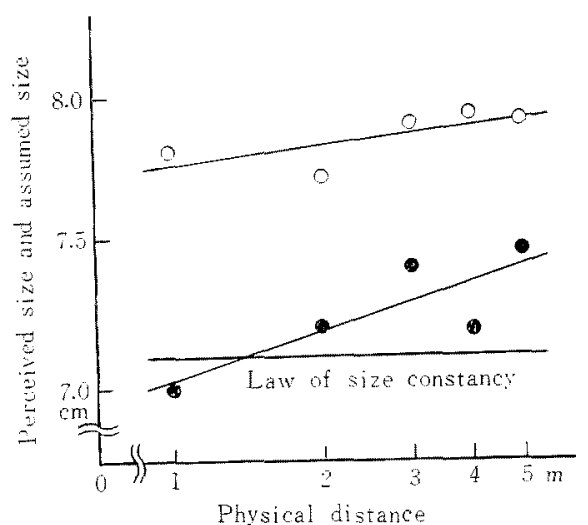

FIG. 1. The perceived size and assumed size as a function of physical distance. The law of size constancy is derived from the normal-size $(7.1 \mathrm{~cm}$ in height) of the cigarette-package in question. The straight lines have been fitted by the method of least squares. The circles represent observed values as follows: open circles, data by Measurement Model I ; black circles, data by Measurement Model II. 
A large reduction-screen was placed at $50 \mathrm{~cm}$ apart from $O$ and a rectangular aperture $(16 \mathrm{~cm}$ in height and $20 \mathrm{~cm}$ in width) was cut out. In order to illuminate the stimuli, a projector with a 75 watt bulb $(100 \mathrm{~V})$ was employed. The projector was always located $40 \mathrm{~cm}$ from the stimulus at each distance.

Procedure. The $O$ sat in front of a table and placed his head on a chin rest. Observation was always made through the aperture mentioned above.

In the case of Measurement Model I, at the outset of experimentation, two extreme stimuli $(4.4 \mathrm{~cm}$ and $11.4 \mathrm{~cm})$ were presented at each distance in order that the $O$ might know the whole range of the stimulus series used. Then, the $O$ was instructed to judge each stimulus as to its magnitude in terms of 7 categories: "very large", "large", "slightly large", " middle", "slightly small", "small", and "very small ". It was particularly emphasized that the $O$ should use all of the categories at each distance.

In the case of Measurement Model II, the $O$ was told to judge each stimulus by referring it to his assumed size (Hastorf, 1950) or assumed objective referent (Ittelson, 1951 b) of the cigarettepackage in quiestion ${ }^{3}$. Judgments were made in terms of 4 categories: "same", "slightly different", "different", and "clearly different". The category "same" was used only when the stimulus presented was coincident with the $O$ 's assumed size. If the $O$ assigned a stimulus to other " different " categories, then he was asked to indicate whether it was in smaller or larger direction than his assumed size. Consequently, the number of category employed was essentially the same as in Measurement Model I.

In both measurement models, the order of presentation of stimulus was random to each $O$ and the experimental order of distance was also random. Experimentation was begun after several preliminary judgments. At each distance, each stimulus was presented 8 times, and hence the total judgments of an $O$ were 88 for each distance. The condition of observation was binocular. All the experimentations were carried out in a dark room.
Results: Data obtained from 6 Os in regard to Measurement Model I are shown in Table 1, whereas data for Measurement Model II are given in Table 2. As is clear from both tables, the data are expressed in terms of frequencies with which each stimulus was assigned to " middle " and "same" category at each distance. The values of perceived size and assumed size ${ }^{4}$ given in the last column of Tables 1 and 2, represent weighted geometric means which are calculated from the following formula:

$$
\log w C M=\sum W_{i} \log X i / \Sigma W_{i}
$$

where $W i$ represents frequency for each stimulus and $X i$ represents physical value of each stimulus.

As shown in Tables 1 and 2, the difference between perceived size and assumed size is remarkable and statistically significant $(t=8.72, d f=4, P<0.001)$. This may entirely be due to the difference between two measurement models, because a common stimulus series was used for both measurement models.

Of importance is the finding that assumed sizes tend toward the normal-size package in comparison with perceived sizes. In other words, constancy of assumed size is higher than that of perceived size.

A plot of the logarithms of perceived size $\left(S_{1}\right)$ and assumed size $\left(S_{2}\right)$ against the logarithms of physical distance $(D)$ is shown in Fig. 1. Two straight lines running among the dots in the figure are estimated from the data given in Tables 1 and 2 by the method of least-squares. Consequently, we obtain

$$
\begin{aligned}
& S_{1}=7.754 D^{0.012} \quad(r=0.850) \\
& \text { and } S_{2}=7.021 D^{0.032}(r=0.839)
\end{aligned}
$$

where $r$ represents coefficient of correlation

${ }^{3}$ Assumed size functions as a standard reference size or an absolute standard size when judging such a stimulus series as in the present experiment.

${ }^{4}$ In this article, the terms percived size and assumed size refer to Measurement Models $I$ and II, respectively. A discussion about 'size' will be seen in later. 
TABLE 3

Frequencies with which each stimulus was assigned to "middle" category at each distance

\begin{tabular}{|c|c|c|c|c|c|c|}
\hline \multirow{2}{*}{$\begin{array}{l}\text { Physical } \\
\text { distance }\end{array}$} & \multicolumn{5}{|c|}{ Stimulus } & \multirow{2}{*}{$\begin{array}{c}\text { Perceived } \\
\text { size }\end{array}$} \\
\hline & $6.5 \mathrm{~cm}$ & 7.1 & 7.8 & 8.6 & 9.6 & \\
\hline $1 \mathrm{~m}$ & 7 & 23 & 28 & 14 & 4 & $7.67 \mathrm{~cm}$ \\
\hline 2 & & 20 & 29 & 31 & 4 & 7.99 \\
\hline 3 & 3 & 13 & 28 & 32 & 6 & 8.05 \\
\hline 4 & 5 & 19 & 28 & 22 & 8 & 7.91 \\
\hline 5 & 1 & 11 & 31 & 32 & 8 & 8.14 \\
\hline
\end{tabular}

TABLE 4

Frequencies with which each stimulus was assigned to "same" category at each distance

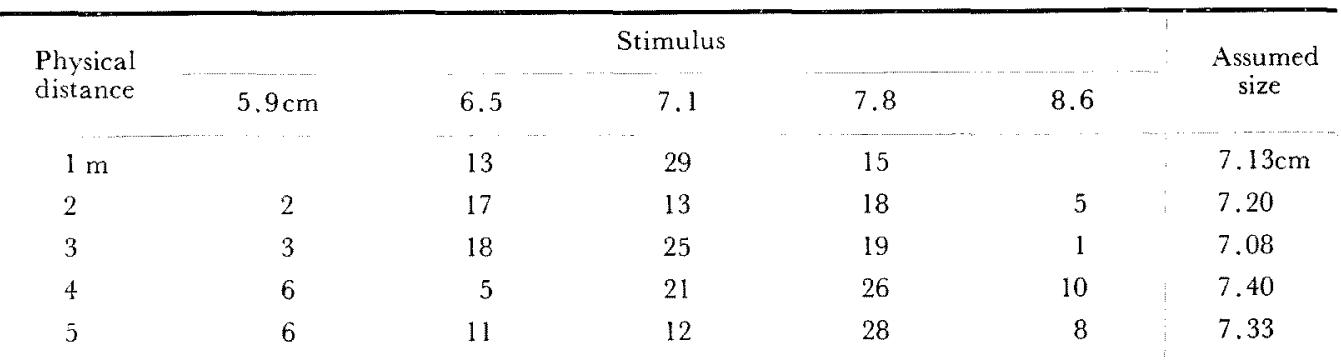

as an indicator of goodness of fit.

Both of the fits are not so good. However, it should be noted that, as Equations (1) and (2) suggest, both perceived size and assumed size increase slightly with increasing physical distance.

\section{EXPERIMENT II}

The present experiment was designed to confirm the findings in Experiment $I$ by using three-dimensional unfamiliar object as stimulus-object.

Observers. Six undergraduate students served as $O_{\mathrm{s}}$. They all were different from the $O_{\mathrm{s}}$ in Exp. I. Half of them participated in Measurement Model I first and II second; the other half in the reverse order.

Stimuli and stimulus arrangements. A white cardboard box was chosen as a sample of threedimensional unfamiliar object. Physical dimension of the box was strictly the same as the

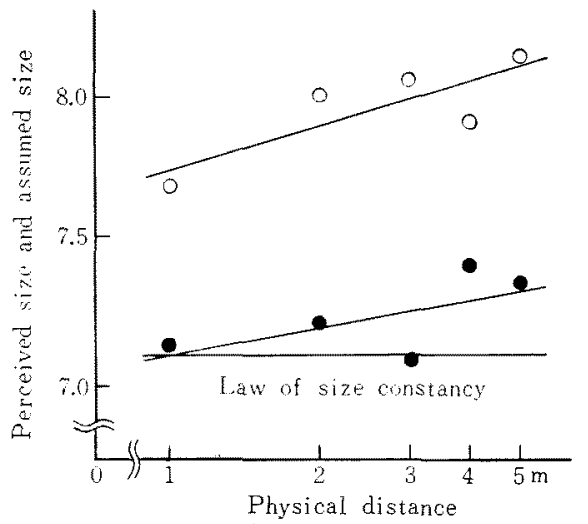

Fig. 2. The perceived size and assumed size as a function of physical distance. The law of size constancy is derived in the same way as in Experiment I. The straight lines have been fitted by the method of least squares. The circles represent observed values as follows: open circles, data by Measurement Model I; black circles, data by Measurement Model II. 
cigarette-package employed in Exp. I. That is to say, the box-stimuli consisted of 11 boxes ranging from $4.4 \mathrm{~cm}$ to $11.4 \mathrm{~cm}$ in height. Presentation distance of the stimuli, the condition of illumination and other conditions were exactly the same as those employed in Exp. I.

Procedure. In Measurement Model I, the $O$ was told to judge, in terms of 7 categories, each stimulus as in Exp. I.

The procedure of Measurement Model II was essentially the same as that of Measurement Model II in Exp. I. However, the following was different: At the outset of experimentation, the $O$ was required to hold the normal-size package of "Peace" in his hands, in order to make (or reinforce) his assumed size. The handling time was about 5 minutes. During the experimentation, the $O$ did not hold anything in his hands.

The observational condition was binocular. All of the experimentations were conducted in the same dark room as in Exp. I. The rest of the procedure was exactly the same as in Exp. I.

Results: Data of Measurement Model I are shown in Table 3, whereas those of Measurement Model II are given in Table 4. The value of perceived size and assumed size is calculated in the same way as in Experiment $\mathbf{I}$.

The difference between perceived size and assumed size is statistically significant $(t=8.32, d f=4, P<0.01)$. Assumed sizes appear smaller than perceived sizes, as shown in Tables 3 and 4 . Obviously, this finding is consistent with that in Experiment I.

In Fig. 2, perceived size $\left(S_{1}\right)$ and assumed size $\left(S_{2}\right)$ are plotted against physical distance $(D)$ in log-log coordinates. We secure the following equations by the method of least-squares:

$$
\begin{aligned}
& S_{1}=7.725 D^{0.030} \quad(r=0.736) \\
& \text { and } \quad S_{2}=7.096 D^{0.019} \quad(r=0.697)
\end{aligned}
$$

The fits are not fully satisfactory. As in

\footnotetext{
' The same procedure, though slightly different, can be found in Makino and Ueno (1963).
}

Experiment I, however, perceived size and assumed size respectively exhibit a tendency to increase with increasing distance.

\section{Discussion}

First of all, we must have some discustions about 'size'.

When considering the problem of size constancy, the concept of size is important. A great deal of analysis, logical as well as phenomenological, has been aimed at clarifying the term 'size' (e.g., Helson, 1936; Boring, 1942, 1952a, 1952b; Joynson, 1949; Hastorf, 1950; Edwards, 1950; Ittelson, 1951b; Gilinsky, 1951; Hochberg \& Hochberg, 1952).

There is a remarkable attempt among workers on visual space perception that perception of size is considered in relation to attitude or set (Einstellung) (e.g., Joynson, 1949; Gibson, 1950, 1952; Gilinsky, 1955; Brunswik, 1956; Carlson, 1960, 1962). It seems, however, that this kind of attempt is an ingenious but inadequate one when clarifying the concept of size. The reason is that observational attitude or set is ambiguous in the sense that it can not hightly be controlled by means of experimental operations.

Rigorous specification of 'size' must be operational. In other words, it must be defined in terms of concrete repeatable operations. In the present study, the term perceived size is defined by Measurement Model I, i.e., by comparing stimuli with each other. Whereas the term assumed size is defined in terms of Measurement Model II, i.e., by comparing stimuli against some absolute standard or personal reference point.

It goes without saying that the abovementioned definitions hold for other terms expressing 'size'. For example, such terms as apparent size (Helson, 1936; Holway \& Boring, 1941; Boring, 1942, p. 289, etc), phenomenal size (Thouless, 1931; Boring, 1942, p. 289, 1952b, etc), relative size (Hochberg \& Hochberg, 1952), relative perceived size (Gilinsky, 1951), etc, 
are definable by Measurement Model $\mathrm{I}^{6}$; on the other hand, the terms estimated size (Boring, 1942, p. 289; Over, 1963, etc), familiar size (Hochberg \& Hochberg, 1952; Mckennell, 1960, etc), real size (Thouless, 1931; Vernon, 1937), apparent absolute size (Joynson, 1949), subjective true size (Gilinsky, 1951), etc, can be defined by Measurement Model II.

The question as to which measurement model is adequate for size constancy under consideration, is of especial importance. It is closely related to perceptual theory. Measurement Model II is considered appropriate from the viewpoint of contemporary theories (e.g., Vernon, 1955; Ittelson, 1951 a, 1960).

Next, we must consider the data obtained in Experiments I and II. Since such a stimulus series as in Experiment I was used, it was predicted, at first, that perceived size would become equal to assumed size. As shown in Tables 1 and 2, however, this prediction is not true. Therefore, the result is directly attributable to the difference between measurement models. The same holds for the data obtained in Experiment II.

As is apparent from Figs. 1 and 2, assumed size as a whole increases with physical distance. This finding is in line with Makino and Ueno's results (1963). The fact that the data of Measurement Model II in Experiment II are quite similar to those of Measurement Model II in Experiment I, suggests a stability of the observer's assumed size (or 'assumption') concerning the cigarette-package in question.

As mentioned before, constancy of assumed size is in general higher than that of perceived size. This result arises neces-

\footnotetext{
${ }^{6}$ It should be noted that the operational definition of size in terms of Measurement Model $I$ is essentially in the same line as Boring's operational thinking: "Phenomenal size, like physical size, is relative and has no meaning except as the relation between objects" (Boring, 1952 b, p. 247).
}

sarily from the nature of the assumed size itself. Makino and Ueno (1963) found the same kind of results with respect to size constancy by the method of two stimuli comparison.

Perceived sizes in Experiments $I$ and II are always higher than the middle of the stimulus series used, as shown in Tables 1 and 3 . This may mainly be due to an asymmetry based on the relativity of discrimination (Stevens, 1957; Stevens \& Galanter, 1957). Of particular interest is the finding that perceived size also shows a tendency to increase with increasing distance.

It is known that the functional relationship between perceived or assumed size and physical distance is expressible in the following equational form: $S=K D^{n}$ (e.g., Kuroda, 1961; Ueno, 1962; Makino \& Ueno, 1963). In the present experiments, however, goodness of fit of this function to the data obtained is not so satisfactory. Therefore, further research would be needed to this point.

As the closing remarks of the present investigation, some comments must be made concerning the two measurement models.

The distinction between order relation and proximity relation in Coombs' system is essentially the same as that between judgments and responses in Torgerson's system $(1958$, p. 48). In so far as the area of psychophysics is concerned, a typical example of order relation can be found in Stevens' category scales or partition scales (Stevens, 1957, 1960). The rating scales used in Helson's AL-theory may be regarded as a compound of order relation and proximity relation (Helson, 1947, 1948, 1959).

\section{SUMMARY}

From the viewpoint of measurement models, size constancy in single stimuli situation was investigated. Two experiments were carried out. The concept of size was discussed with two measurement models. 


\section{REFERENCES}

Bolles, R. C., \& Bailey, D. E. Importance of object recognition in size constancy. 7. exp. Psychol., 1956, 51, 222-225.

Borivg, E. G. Sensation and perception in the history of experimental psychology. New York: Appleton-Century, 1942.

Boring, E. G. Visual perception as invariance. Psychol. Rev., 1952, 59, 141-148. (a)

Boring, E. G. The Gibsonian visual field. Psychol. Rev., 1952, 59, 246-247. (b)

Brunswik, E. Perception and the representative design of psychological experiments. Berkeley: Univ. Calif. Press, 1956.

Carlson, V.R. Overestimation in size-constancy judgments. Amer. 7. Psychol., 1960, 73, 199 213.

Carlson, V. R. Size-constancy judgments and perceptual compromise. 7. exp. Psychol., 1962, $63,68-73$.

Coombs, C. H. A theory of psychological scaling. Lniw. Mich. Engng. Res. Inst. Bull., 1952, No. 34.

Coombs, C. H. The theory and methods of social measurement. In L. Festinger \& D. Katz (Eds.), Research methods in the beharioral sciences. New York: Dryden, 1953, Pp. 471-535.

Coonis, C. H. A theory of data. Psychol. Rev, $1960,67,143-159$.

Edwards, W. Emmert's law and Euclid's optics. Amer. 7. Psychol., 1950, 63, 607-612.

Grsson, J. J. The perception of the visual world. Boston: Houghton Miffin, 1950.

Gibson, J.J. The visual field and the visual world: a reply to Professor Boring. Psychol. Reu., 1952, 59, 149-151

Ginnsky, A. S. Perceived size and distance in visual space. Psychol. Rev., 1951, 58, 460-482.

Gilinsky, A. S. The effect of attitude upon the perception of size. Amer. 7. Psychol., 1955, 68, 173-192.

Hastorf, A. H. The influence of suggestion on the relationship between stimulus size and perceived distance. 7. Psychol., 1950, 29, 195 217.

Helson, H. Size-constancy of the projected afterimage. Amer. 7. Psychol., 1936, 48, 638-642.

Helson, H. Adaptation-level as frame of reference for prediction of psychophysical data. Amer. 7. Psychol., 1947, 60, 1-29.

Helson, H. Adaptation-level as a basis for a quantitative theory of frames of reference. Psychol. Rev., 1948, 55, 297-313.
Helson, H. Adaptation level theory. In S. Koch (Ed.), Psychology: A study of a science. Vol. 1. New York: McGraw-Hill, 1959.

Hochberg, G. B., \& HochberG, J. E. Familiar size and the perception of depth. 7. Psychol., $1952,34,107-114$.

Holway, A. H., \& Boring, E. G. Determinants of apparent visual size with distance variant. Amer. 7. Psychol., 1941, 54, 21-37.

Ittelson, W. H. The constancies in perceptual theory. Psychol. Rev., 1951, 58, 285-294. (a)

Itrelson, W. H. Size as a cue to distance: static localization. Amer. 7. Psychol., 1951, 64, 5467. (b)

ItTelson, W. H. Visual space perception. New York: Springer, 1960.

Joynson, R. B. The problem of size and distance. Quart. F.exp. Psychol., 1949, 1, 119-135.

Kuroda, T. Experimental studies on size constancy. Bull. Lit. Fac. Kyushu Univer., Kyushu Psychological Studies, 1961, 7, 59-102.

Makno, T. A methodological investigation of 'size constancy'. Jimbun Kenkyu, Studies in the Humanities (F. Lit. Assoc. Osaka City Univer.), $1954, \mathbf{5}, 1-23$.

Makino, T., \& Ueno, T. Methodological studies of size constancy (1): Size constancy measured by two experimental methods. Jap. Psychol. Res., 1963, 5, $91-102$.

Martrus, G. Ueber die scheinbare Grösse der Gegenstände und ihre Beziehung zur Grösse der Netzhautbilder. Windts Phil. Stud., 1889, 5, 601-617.

Mckennell, A. C. Visual size and familiar size: individual differences. Brit. F. Psychol., 1960, 51, 27-35.

OVer, R. Size- and distance-estimates of a single stimulus under different viewing conditions. Amer. 7. Psychol., 1963, 76, 452-457.

Stevens, S. S. On the psychophysical law. Psychol. Rev., 1957, 64, 153-181.

Stevens, S. S. Ratio scales, partition scales and confusion scales. In H. Gulliksen \& S. Messick (Eds.). Psychological scaling: Theory and applications. New York: John Wiley, 1960, Pp. 49-66.

Stevens, S. S., \& Galanter, E. H. Ratio scales and category scales for a dozen perceptual continua. 7. exp. Psychol., 1957, 54, 377-411.

Thouless, R. H. Phenomenal regression to the real object. Brit. 7. Psychol., 1931, 21, 339$359 ; 22,1-30$.

Torgerson, W. S. Theory and methods of scaling. New York: John Wiley, 1958. 
Ueno, T. The size-distance invariance hypothesis and the psychophysical law. Jap. Psychol. Res., 1962, 4, 99-112.

Vernon, M. D. The perception of distance. Brit. 7. Psychol., 1937, 28, 115-149.
Vernon, M. D. The functions of schemata in perceiving. Psychol. Rev., 1955, 62, 180-192.

(Received Nov. 25, 1963) 